\title{
ANTI-PLAGIARISM WEBSITES AND TOOLS
}

\section{MAHADU MANOHARRAO SHINDE ${ }^{1}$, CHANDRAKANT DAGADU SHETE ${ }^{2}$,} PAWANRAJ JAGDISH DESHMANE ${ }^{3}$ \& SUBHADRA AMRUT MUNJEWAR ${ }^{4}$

\author{
${ }^{1,2,3}$ College of Dairy Technology, Udgir, District-Latur (Maharashtra), A Constituent College of Maharashtra Animal and
}

Fishery Sciences University, Nagpur, India

${ }^{4}$ Dili Patil Nilengekar Mahavidyalya, Udgir Dist. Latur, Maharashtra, India

ABSTRACT
In this paper, the discussion is about free plagiarism checker websites and tools, which are the most effective
and up-to-date to detect copied content. This study is on the introduction of plagiarism, its types and the plagiarism
websites. The main objective of this paper is to create an awareness about plagiarism software among research scholars
and faculty members and help them to become successful by avoiding plagiarism.
KEYWORDS: Plagiarism, Anti-Plagiarism, Free plagiarism Software \& etc

Received: Oct 01, 2017, Accepted: Oct 30, 2017, Published: Mar 03, 2018, Paper Id: IJCMSAPR20181

\section{INTRODUCTION}

The research community currently faces the most challenging issues of plagiarism. Although plagiarism is known for centuries, the widespread use of computers and the advent of the Internet made it relatively easy to plagiarize other's work. Duplication happens sometimes when our writings match someone else's writing style. Plagiarism mostly happens due to the rise in the number of websites and blogs. Many times our writing styles match influential article we have recently read. Whatever may be the cause of duplication, it is always a pain for both the ends. That is why, it is of great necessity to put a check on plagiarism. This paper will take you through the best online plagiarism checker tools and services that can be used to detect duplication of contents and create original articles.

Plagiarism is increasing day by day and has become a worldwide problem. This is mainly because of the increase in the number of online publications. We can compare the given document with the target/original document using plagiarism detection technique Plagiarism detection is now as easy as plagiarizing a document. A number of anti-plagiarism softwares used to detect plagiarism are available either freely or commercially. It is not affordable for an individual to purchase the software because as the commercial ones are too expensive. This paper discussed about the plagiarism detection software that can be freely downloaded.

\section{WHAT IS PLAGIARISM?}

\section{Plagiarism Meaning}

Plagiarism is borrowed from the Latin language, meaning "to kidnap." According to the Merriam Webster Online Dictionary, plagiarism means

- To snitch and pass off the words and ideas of another as one's own idea. 
- Use another's work without crediting the source.

- To commit classical or scholarly theft.

- $\quad$ Presenting as new or original idea or product derived from an existing source.

Plagiarism essentially means "imitation of someone else's work," without giving the real writer his credits.

\section{Plagiarism Types}

Based on their detection difficulty, plagiarism can be divided into about 15 types (Park, 2004; Hire math \& Otari, 2014;) as listed below.

- Clone plagiarism: Taking someone else's work entirely.

- Copy-and-paste plagiarism: Copying large parts of someone else's work.

- Re-tweets plagiarism: Contains correctly quoted text but relies too much on someone else's work.

- $\quad$ Recycle or auto plagiarism: Publishing the same work many times.

- $\quad$ Find-replace or word-switch plagiarism: Using synonyms for words in someone else's work.

- Hybrid plagiarism: Combining judiciously quoted and unquoted parts of someone else's text.

- Mash up plagiarism: Copying material from different sources.

- Error plagiarism: Using incorrect citation.

- Aggregator plagiarism: No originality in the work, although it contains references to the original work.

- Style plagiarism: Paraphrasing to the extent that the original text is unrecognizable, but the structure of both documents is similar (essential schemes, main arguments, or examples coincide).

- Translation plagiarism: Translating someone else's work into another language.

- Idea plagiarism: The main idea of the work is not original, but it is masked by the plagiarist's knowledge.

- Graphics plagiarism: Using a figure or a picture without permission.

- Source-code plagiarism: Taking the source code in computer programming.

- Ghost write plagiarism: Contracting another person or website to produce the work for someone.

\section{TOP FREE PLAGIARISM DETECTION TOOLS}

\section{Grammarly}

Grammarly is a tool which not only detects plagiarism issues of the texts, but also proofreads the whole text, giving an option to correct more than 205 types of grammatical errors. It can also examine plagiarism against more than 8 billion web pages in just a few seconds, giving instant report. Grammarly is considered one of the top plagiarism detection tools and best automated proof readers, with the capability of correcting the errors instantly. For a professional content writer, this tool can be of great help in proofreading and ruling out the grammatical as well as spelling errors. It also enhances one's vocabulary. Grammarly is the most effective online duplicate content checker tool for teachers and students 
and reveals the percentage of copied contents in the essays, journals or in assignment writings. It is the best plagiarism checker software apart from having grammar checker features.

\section{Plag Scan}

Being a highly recommended plagiarism detection tool for teachers, professors and academic professionals, Plag Scan is a web-based detection tool, enabling one to either copy and paste student assignments or upload the assignment to be scanned for plagiarized content. Plag. The scan site doesn't offer as much information as any other sites on just what's included in the database they're checking papers against. Its various lavish features offer the option to customize as per one's requirements. One can check the trial version before subscribing.

\section{White Smoke}

White smoke has a very robust plagiarism checker feature and a very important online language and grammar checker tool. This tool removes the duplicate content in the copied text and saves the site's ranking and online reputation. It is a good alternative and a close competitor for the Grammarly plagiarism checker. Article Checker.

Since it doesn't insist on registration or subscription, Article Checker used with great pleasure. There is no need of uploading this file before checking, but can just copy and paste the text and get it checked in a few seconds. It is one of the most accessible plagiarism checker tools to detect duplication. The main drawback of this tool is its dissatisfying results at times.

\section{PLAGIARISM CHECKER}

This tool doesn't require any downloading or installation and is easy to use with the help of the given detailed instructions This software helps in checking whether the student has copied the content from the Internet. This checker has an option called "Author" that enables to check whether any others have plagiarized the author's work online. Here you need to press "Enter" after each phrase, as it searches phrases separately.

\section{Dupli Checker}

Dupli Checker is a entirely free of cost tool which would be one's fullest satisfaction. It does not charge a single penny and is a $100 \%$ free checker tool and is very easy to use. Here you can just copy-paste, or upload your thesis, article or the content of the website and analyze it and get the report in a few seconds. Fifty search can be performed by registered users and only 1 search can be performed by unregistered users. Definitely it is not an alternative to Grammarly but can be used to detect duplication and check for traces of copied contents.

\section{Plagiarism Check}

Unlike many other free plagiarism checker tools, Plagiarism Check fixes restrictions by limiting the word count. An unlimited number of pages or papers can be checked using a plagiarism checker, without the concern of losing the file formats. Its features accept all kinds of formats. Certain plagiarism tools may not be accessible from all locations, hence enabling its access from anywhere in the world. In addition, even the plagiarism report can be easily downloaded. The authenticity of the product is a big question, causing worries to many of the users.

\section{Copy Leaks}

This software provides the plagiarism scan of the entire website, supporting only for online content. It can detect 
content duplication in more than 60 trillion pages over the Internet and supports of multiple file formats in any language. The API of Copy Leaks enables integrating Copy Leaks service, including it as part of one's product. In Copy Leaks, an user ID need to be created. Although now it is free of cost, shortly a premium subscription will be added for long-term use.

\section{Small SEO Tools}

Small SEO Tools is a platform where several tools with highly lavish features can be obtained. Apart from detecting plagiarism, it also offers a host of other useful SEO tools such the Article Rewriter, Keyword Position, Online Ping Website Tool, Back link Checker, Back link Maker, Link Tracker, Google Page Rank Checker, Domain authority checker, Word Count Checker, Spell Checker tool, and many more. Although its plagiarism checker is a basic type, many like using it because it is totally free of cost.

\section{Plag Tracker}

Plag Tracker can scan more than 20 million academic works to detect plagiarism. Although it provides a detailed report, the report is not $100 \%$ accurate and leading one to use an extra plagiarism detection tool for further assurance.

\section{Plagiarisma}

A plagiarism software for Windows and 190+ languages supported is Plagiarisma, which is a free ware. In this software, the content is searched in a URL, reporting only exact matches. The software demonstrated very stringent usage, that is, the user cannot exceed 3 times per day.

\section{Plagium}

Although Plagium is a free ware for checking plagiarism, it has several features. This tool has the capability to check for plagiarism of the content published even the social media sites such as the Facebook, Twitter, etc. Plagiarism Checker.

Instant checking and immediate report generation are the features of Plagiarism Checker. This tool is useful for teachers and authors but unfortunately it is not a free ware.

\section{Paper Rater}

The free software Paper rator has three useful tools, namely, grammar checking, writing suggestions and plagiarism detection. Paper rator is considered handy in detecting unoriginal content in school projects and other essays of students and academic documents.

\section{Dust Ball}

The popular and simple tool Dust ball is used to check copied content, that is, checking for plagiarized content. The free version is effective for detecting any traces of unoriginal content, but they also have a paid version.

\section{PLAGIARISM CHECKER PLUGIN FOR WORD PRESS}

Among the users of Word Press, the happiness never ends. In this tool, all the tasks have separate plugins, which can be located on one's dashboard and alerts the when there are copied sentences or phrases, thereby saving one from the curse of penalties of the search engine. Hence, it is considered the best one. 


\section{Viper}

Viper is a $100 \%$ free ware, scanning more than 10 billion resources such as academic essays and other online sources. Viper's best feature is to offer the side-by-side plagiarism comparison sand can be used only by Microsoft Windows users. Check For Plagiarism

Involving the combined efforts of professionals, computer scientists, and the academicians, Check For Plagiarism possesses a great number of features. It is equally helpful to the students, teachers, professionals, writers, and the publishers to keep a check on the plagiarism evil. This is known for its highly popular plagiarism detection aspects, with excellent accuracy and user-friendliness. It is frustrating for certain users because of the lack of free trial version.

\section{Copy Scape}

With Copys cape, copied contents can be detected on your blog or website within a matter of seconds. By simply entering the site's URL or use the inbuilt Site liner, the Copy scape would generate a report showing similarity with other websites or as to how much of the content has been copied, thus chasing the content thieves.

\section{Que Text}

Que text involves easy interface and is a $100 \%$ free ware. For this software, only the copy-paste the content, without uploading the files as a whole.

\section{Search Engine Reports}

Search engine reports check traces of copied content across several other search engines, including Yahoo and Bing. The reasoning involves dividing the submitted text into smaller bunches, thus enabling checking for any similar content or reviewing for plagiarism of essay already published across the web.

\section{CONCLUSIONS}

Plagiarized materials can be identified using the various software, websites and tools mentioned in this paper, thus ascertaining that articles, documents or research work of any form and capacity are not plagiarized and thereby the violation of the copyright of the publisher and the authors are arrested.

\section{REFERENCES}

1. https://copyleaks.com

2. http://www.paperrater.com

3. http://plagiarisma.net

4. https://www.plagiarismsoftware.net

5. http://www.plagium.com

6. http://www.plagscan.com

7. http://www.duplichecker.com

8. https://plagiarismcheck.org

9. http://smallseotools.com 
10. http://www.plagium.com/

11. https://www.paperrater.com

12. http://www.dustball.com

13. http://www.checkforplagiarism.net

14. http://www.copyscape.com

15. https://searchenginereports.net

16. http://www.plagtracker.com

17. http://www.quetext.com

18. http://www.scanmyessay.com

19. https://www.grammarly.com

20. http://www.plagscan.com

21. http://www.whitesmoke.com

22. http://smallseotools.com/plagiarism-checker

23. http://www.merriam-webster.com

24. http://www.duplichecker.com 